\title{
Erratum to: Reserpine Is the New Addition into the Repertoire of AcrB Efflux Pump Inhibitors [Molecular Biology, 2019, Vol. 53, No. 4, pp. 596-605]
}

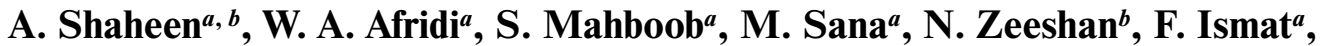 \\ O. Mirzac ${ }^{c}$, M. Iqbal $^{a}$, and M. Rahman ${ }^{a, *, * *}$ \\ ${ }^{a}$ Drug Discovery and Structural Biology group, Health Biotechnology Division, National Institute \\ for Biotechnology and Genetic Engineering (NIBGE), Faisalabad, 44000 Pakistan \\ ${ }^{b}$ Department of Biochemistry and Biotechnology, University of Gujrat, Hafiz Hayat Campus, Gujrat, 50700 Pakistan \\ ${ }^{c}$ Department of Drug Design and Pharmacology, Faculty of Health and Medical Sciences, \\ University of Copenhagen, Copenhagen, 1165 Denmark \\ *e-mail: moazur.rahman@fulbrightmail.org \\ **e-mail:moaz@nibge.org
}

Submitted August 26, 2019; accepted for publication August 26, 2019

DOI: $10.1134 / \mathrm{S} 0026893319090012$

On page 596, the names of the two first authors with the indications of their affiliations and the note for both authors should be:

A. Shaheen ${ }^{a, b \#}$, W. A. Afridi ${ }^{a \#}$

\#These authors contributed equally to this work.

The original article can be found online at

https://doi.org/10.1134/S0026893319040113 